\title{
MORCEGOS DO PARQUE ESTADUAL DA SERRA DA TIRIRICA, RIO DE JANEIRO, BRASIL (MAMMALIA, CHIROPTERA) ${ }^{1}$
}

\author{
Sylvia Ceppas Teixeira ${ }^{2}$ \\ Adriano L. Peracchi ${ }^{2}$
}

\begin{abstract}
Bats from Serra da Tiririca State Park, Rio de Janeiro, Brazil. (MAmmalia, Chiroptera). A preliminary survey of bats species from the Serra da Tiririca State Park is presented. Two hundred and seventy two bats of 20 species were collected. Comments about reproduction and feeding habits of the captured species are included.

KEY WORDS. Chiroptera, bats, reproduction, feeding habits
\end{abstract}

O Parque Estadual da Serra da Tiririca, situado no estado do Rio de Janeiro e recentemente implantado pelo Instituto Estadual de Florestas, constitue uma unidade de conservação de especial interesse, dada a sua proximidade dos grandes centros urbanos formados pelas cidades de Niterói e São Gonçalo.

Face a inexistência de informações sobre os mamiferos do Parque, apresenta-se um levantamento preliminar das espécies de quirópteros que ocorrem na área, fornecendo dados sobre a reprodução e hábitos alimentares de algumas espécies.

\section{MATERIAL E MÉTODOS}

O Parque Estadual da Serra da Tiririca, abrangendo uma área de $17,9 \mathrm{~km}^{2}$, está situado na divisa dos municípios de Niterói e Maricá e estende-se, desde a costa, junto à praia de Itacoatiara, até o Engenho do Mato, município de São Gonçalo. A região apresenta temperatura anual média de $23^{\circ} \mathrm{C}$ e uma altitude média de $250 \mathrm{~m}$ (PONTES 1987).

A vegetação em grande parte não é mais constituída de floresta primária, devido à destruição acarretada pela implantação de fazendas, sítios e, principalmente, pela monocultura de bananeiras (Musa spp.). Entretanto, a cobertura vegetal exibe atualmente vários estágios de regeneração e nas áreas mais íngremes, encontram-se remanescentes da Mata Atlântica que outrora recobria a região.

Os trabalhos de campo foram realizados no Sítio Três Nascentes $\left(22^{\circ} 52^{\prime} \mathrm{S}\right.$, $\left.43^{\circ} 18^{\prime} \mathrm{W}\right)$, localizado no interior do Parque e que detém excepcional trecho de Mata Atlântica remanescente, por apresentar relevo bastante acidentado. Esses trabalhos

1) Trabalho dos laboratórios da Área de Zoologia do Instituto de Biologia da Universidade Federal Rural do Rio de Janeiro. Com auxilio do CNPq.

2) Instituto de Biologia, Universidade Federal Rural do Rio de Janeiro. Caixa Postal 74503 , 23851-970 Itaguai, Rio de Janeiro, Brasil. Bolsista do CNPq. 
foram realizados no período de maio de 1993 a janeiro de 1995, no horário de 17 às 22 horas, utilizando-se redes japonesas (mist nets) distendidas em trilhas no interior da mata e em lugares descampados, próximos às plantações de banana. Essas redes foram armadas de tal forma que o tirante inferior se situasse de 0,50 a 2,50m de altura. As coletas relizadas proporcionaram a captura de 272 exemplares, que foram em sua maioria liberados após a identificação e anotações pertinentes, tendo sido sacrificados até cinco exemplares de cada espécie a fim de ser possível a organização de coleção sinóptica, representativa dos morcegos da região. Os exemplares sacrificados foram taxidermizados ou conservados em ácool à $70^{\circ} \mathrm{GL}$, após fixação em formol $10 \%$ e foram incorporados à coleção Adriano L. Peracchi, atualmente depositada no Instituto de Biologia da Universidade Federal Rural do Rio de Janeiro.

Na citação das espécies adotamos a ordem sistemática proposta por CABRERA (1958) e a nomenclatura apresentada por KOOPMAN (1993).

\section{RESULTADOS}

Phyllostomidae

\section{Micronycteris Gray, 1866 Micronycteris megalotis (Gray, 1842)}

A análise do conteúdo gastrointestinal de um macho, capturado no mês de abril de 1994, revelou fragmentos de insetos.

Material examinado. Uma fêmea 02-VI-1993; um macho 17-IV-1994.

\section{Micronycteris minuta (Gervais, 1856)}

Foram capturados dez exemplares com rede armada próximo a um córrego, no interior da mata, sendo que no mês de setembro foram colecionadas quatro fêmeas grávidas e no mês de fevereiro, uma fềmea lactante. A análise do conteúdo gastrointestinal de alguns exemplares revelou fragmentos de Lepidoptera e de outros insetos não identificados.

Material examinado. Duas fêmeas 21-V-1993; um macho 02-VI-1993; uma fêmea 12-VII-1993; três fềmeas 06-IX-1993; uma fêmea 17-IX-1993; um macho 05-XII-1993; uma fêmea 05-II-1994.

\section{Tonatia Gray, 1827 \\ Tonatia silvicola (d'Orbigny, 1836)}

Um macho escrotado dessa espécie pouco freqüente foi capturado com rede armada no interior da mata, em setembro de 1993. O exame do tubo digestivo desse exemplar não revelou qualquer vestígio de alimento.

Material examinado. Um macho 06-IX-1993. 


\section{Trachops Gray, 1847 \\ Trachops cirrhosus (Spix,1823)}

Um macho foi capturado em maio de 1993, com rede armada numa trilha no interior da mata. $\mathrm{O}$ exame do conteúdo gastrointestinal revelou fragmentos de insetos não identificados.

Material examinado. Um macho 21-V-1993.

\section{Chrotopterus Peters, 1865 Chrotopterus auritus (Peters, 1856)}

Um macho foi colecionado em novembro de 1994, com rede distendida no interior da mata. Nas fezes desse exemplar foram encontrados fragmentos de insetos não identificados.

Material examinado. Um macho 06-XI-1994.

\section{Glossophaga E.Geoffroy,1818 Glossophaga soricina (Pallas,1766)}

Cinco fêmeas e dois machos dessa espécie polinívora foram capturados.

Material examinado. Duas fềmeas 02-VI- 1993; duas fềmeas 12-VII-1993; um macho 05-II-1994; uma fêmea 17-IV-1994; um macho 06-XI-1994.

\section{Anoura Gray, 1838 Anoura caudifer (E.Geoffroy,1818)}

Dezessete exemplares dessa espécie polinívora foram colecionados. Machos escrotados foram capturados nos meses de fevereiro, março, maio e outubro. Uma fêmea grávida foi capturada em outubro. O exame do conteúdo gastrointestinal de três exemplares revelou fragmentos de insetos e pólen de mirtáceas, bombacáceas e leguminosas.

Material examinado. Um macho e três fêmeas 21-V-1993; dois machos e duas fêmeas 12-VII-1993; um macho 08-VIII-1993; uma fêmea 05-XII-1993; uma fêmea e dois machos 05-II-1994; um macho 25-III-1994; um macho 21-V-1994; um macho e uma fêmea 05-X-1994.

\section{Carollia Gray, 1838}

\section{Carollia perspicillata (Linnaeus, 1758)}

Essa foi a espécie mais frequente na área estudada, tendo sido capturados 108 exemplares. De três fêmeas colecionadas no mês de janeiro, duas eram lactantes. Em fevereiro, três fềmeas lactantes foram capturadas, sendo que uma carregava 0 filhote. Outra fêmea lactante foi colecionada no mês de março e de dez fêmeas encontradas em maio, somente uma era lactante. Fêmeas grávidas foram capturadas nos meses de março (2), setembro (11), novembro (2) e dezembro (3). De sete 
machos obtidos em janeiro, um estava escrotado. Em abril, de três machos capturados, um estava escrotado, enquanto que em maio, de 12 machos colecionados, três estavam nesta condição. No mês de setembro, de três exemplares encontrados, um estava escrotado.

Material examinado. Doze machos e 10 fêmeas 21-V-1993; cinco fêmeas e cinco machos 02-VI-1993; três machos e cinco fêmeas 12-VII-1993; um macho 20-VII-1993; um macho e uma fềmea 08-VIII-1993; um macho 15-VIII-1993; dois machos 31-VIII-1993; três machos e oito fêmeas 06-IX-1993; quatro fêmeas 17-IX-1993; cinco fêmeas e sete machos 05-XII-1993; um macho e quatro fêmeas 05-II-1994; quatro fêmeas e quatro machos 25-III-1994; duas fêmeas e três machos 17-IV-1994; uma fêmea 21-V-1994; duas fêmeas e quatro machos 06-XI-1994; três fêmeas e sete machos 11-I-1995.

\section{Sturnira Gray, 1842 \\ Sturnira lilium (E.Geoffroy, 1810)}

Uma fêmea e um macho dessa espécie, pouco freqüente na região, foram capturados com redes armadas em trilha no interior da mata.

Material examinado. Uma fêmea 02-VI-1993; um macho 06-XI-1994.

\section{Platyrrhinus Saussure, 1860 Platyrrhinush lineatus (E.Geoffroy,1810)}

Foram capturados em uma só noite, no mês de agosto, 25 exemplares dessa espécie, com redes armadas dentro da mata, junto à uma figueira (Ficus gomeleira Kunth \& Bouche) em frutificação. Nessa ocasião, de dez fêmeas colecionadas, quatro estavam grávidas e três eram lactantes. Outra fêmea grávida foi capturada no mês de outubro. O exame do conteúdo gastrointestinal de um dos exemplares revelou fragmentos de insetos.

Material examinado. Quinze machos e dez fêmeas 08-VIII-1993; uma fêmea 05-X-1994.

\section{Platyrrhinus sp.}

Junto à mesma figueira mencionada anteriormente e, na mesma ocasião, foram capturadas duas fêmeas e um macho cujos caracteres não permitiram considerá-los como P.lineatus. Uma das fêmeas encontradas estava grávida.

Material examinado. Duas fêmeas e um macho 08-VIII-1993.

\section{Vampyressa Thomas, 1900 Vampyressa pusilla (Wagner,1843)}

Um macho dessa espécie pouco frequente foi capturado em área descampada, próximo à plantação de bananeiras. Esse exemplar, colecionado em agosto, estava escrotado.

Material examinado. Um macho 31-VIII-1993. 


\section{Chiroderma Peters, 1860 \\ Chiroderma villosum Peters, 1860}

Espécie assinalada pela primeira vez para o Estado do Rio de Janeiro. Em agosto de 1993 foram capturados dois machos, duas fêmeas grávidas e uma fêmea lactante dessa espécie, com o auxílio de redes armadas junto à figueira mencionada anteriormente, onde foram colecionados os exemplares de $P$.lineatus referidos, bem como 21 exemplares de Artibeus lituratus.

Material examinado. Dois machos e três fêmeas 08-VIII-1993.

\section{Chiroderma sp.}

Um macho colecionado na mesma ocasião dos exemplares de C.villosum. Material examinado. Um macho 08-VIII-1993.

\section{Artibeus Leach, 1821 Artibeus fimbriatus Gray, 1838}

Espécie assinalada pela primeira vez para o Estado do Rio de Janeiro. Seis exemplares, quatro fêmeas e dois machos foram colecionados com redes armadas no interior da mata. Uma das fêmeas capturadas no mês de julho era lactante.

Material examinado. Duas fềmeas 21-V-1993; um macho 02-VI-1993; duas fêmeas 12-VII-1993; um macho 18-IX-1993.

\section{Artibeus lituratus (Olfers,1818)}

Dez machos, estando dois escrotados e onze fêmeas, sendo seis grávidas e uma lactante, foram capturados com o auxílio de redes armadas próximo à uma figueira em frutificação, no interior da mata, no mês de agosto. Nessa ocasião foram obtidos, também, exemplares de Platyrrhinus lineatus, Platyrrhinus sp., Chiroderma villosum e Chiroderma sp.. Ainda no mesmo mês foram colecionados mais sete machos, estando três escrotados e cinco fêmeas, sendo uma lactante. Outros machos escrotados foram observados nos meses de fevereiro e março. Fêmeas grávidas foram obtidas em fevereiro e setembro, enquanto fềmeas lactantes foram encontradas em janeiro, abril e dezembro.

Material examinado. Um macho 21-V-1993; um macho e uma fềmea 02-VI1993; um macho e uma fêmea 12-VII-1993; dez machos e onze fêmeas 08-VIII1993; sete machos e cinco fêmeas 15-VIII-1993; duas fềmeas 06-IX-1993; um macho e uma fêmea 05-XII-1993; dois machos e uma fêmea 05-II-1994, quatro machos 25-III-1994; um macho e três fêmeas 17-IV-1994; uma fềmea 11-I-1995.

\section{Artibeus obscurus Schinz,1821}

Espécie assinalada pela primeira vez para o Estado do Rio de Janeiro. Cinco fêmeas grávidas foram capturadas no mês de setembro e outras duas, também grávidas, em janeiro. Um macho escrotado foi colecionado em agosto e de dois machos obtidos em setembro, um estava nessa condição. No mês de abril, de dois 
machos colecionados, um estava escrotado e o outro era monorquídeo. No exame do conteúdo gastrointestinal de um exemplar foram encontrados fragmentos de insetos e sementes.

Material examinado. Dois machos 21-V-1993; duas fêmeas 02-VI-1993; um macho 15-VIII-1993; dois machos e quatro fêmeas 06-IX-1993; uma fêmea 17-IX1993; um macho 05-XII-1993; dois machos 17-IV-1994; um macho e duas fêmeas 11-I-1995.

\section{Desmodontidae}

\section{Desmodus Wied-Neuwied,1826 Desmodus rotundus (E.Geoffroy,1810)}

Cinco exemplares dessa espécie hematófaga foram colecionados na área, sendo que de dois machos capturados em dezembro, um estava escrotado. Outro macho, igualmente escrotado foi observado em fevereiro.

Material examinado. Uma fêmea 12-VII-1993; uma fềmea 08-VIII-1993; dois machos 05-XII-1993; um macho 05-II-1994.

\section{Diphylla Spix,1823}

\section{Diphylla ecaudata Spix,1823}

Um macho e uma fêmea dessa espécie hematófaga foram capturados no interior da mata em novembro e janeiro, respectivamente.

Material examinado. Um macho 06-XI-1994; uma fêmea 11-I-1995.

\section{Vespertilionidae}

\section{Myotis Kaup,1829}

\section{Myotis nigricans (Schinz,1821)}

Um macho e uma fêmea grávida dessa espécie insetívora foram capturados em setembro e março, respectivamente.

Material examinado. Um macho 18-IX-1993; uma fêmea 25-III-1994.

\section{REFERÊNCIAS BIBLIOGRÁFICAS}

Cabrera, A. 1958. Catálogo de los mamíferos de America del Sur. Rev. Mus. Argent. Cienc. Nat. zool. 4 (1): XVI+307.

Koopman, K.F. 1993. Order Chiroptera, p. 137-241. In: D.E. WiLson \& D.M. REEDER (Eds). Mammal species of the world. A taxonomic and geographic reference. 2nd ed., Smith. Inst. Press, p. XVIII+1206.

PONTES, J.A.L. 1987. Serra da Tiririca, RJ necessidade de conservação (1 ${ }^{\mathrm{a}}$ contribuição). Bol. Fund. Bras. Cons. Nat., Rio de Janeiro, 22: 89-94.

Recebido em 02.V.1995; aceito em 13.V.1996. 